\title{
Single Grain Si TFTs for RF and 3D ICs
}

\author{
R. Ishihara, A. Baiano, T. Chen, J. Derakhshandeh, M.R. Tajari Mofrad, M. Danesh, N. \\ Saputra, J. Long and C.I.M. Beenakker
}

Delft University of Technology, Delft Institute of Microsystems and Nanoelectronics (DIMES), Delft, The Netherlands

\begin{abstract}
Single-grain Si TFTs have been fabricated using accurate 2D location control of large Si grain with the $\mu$-Czochralski process. TFTs fabricated inside the crystalline islands of $6 \mu \mathrm{m}$ show a mobility $\left(600 \mathrm{~cm}^{2} / \mathrm{Vs}\right)$ as high as that of the SOI counterpart, despite of the low-temperature $\left(<350^{\circ} \mathrm{C}\right)$ process. By applying a tensile stress into the grain, the mobility surpasses even the SOI counterparts. We have succeeded in controlling crystallographic orientation of the location-controlled $\mathrm{Si}$ grains as well, by combination of metal induced lateral crystallization and the microCzochralski process. Owing to the orientation control, uniformity in device properties approaches to the level of the SOI counterpart. Using the high performance single-grain (SG) Si TFTs, we have fabricated RF amplifier. The cut-off frequency of the RF device is $5.5 \mathrm{GHz}$ with a channel length of $1.5 \mu \mathrm{m}$. We have even succeeded to stack two SG-TFT layers with which CMOS inverters were fabricated. This will open several new applications in TFTs of RF wireless communication, 3D-ICs with device level integration, and flexible electronics.
\end{abstract}

\section{Introduction}

Thin-film transistors (TFTs) using amorphous silicon (a-Si) and low-temperature poly-Si (LTPS) have been successfully applied to active matrix liquid crystal displays (AMLCDs). The basic structure, a thin semiconductor layer on an insulating substrate, dates from the very first invention of the field effect transistor (1). Because it was difficult to obtain a single-crystalline Si layer on a insulator, MOSFETs have chosen the bulk crystalline Si substrate for the channel material. As oppose to the ULSI, the TFTs had been facing difficulty in obtaining the single-crystalline channel material for a long time. This has restricted TFT's performance and the applications as shown in Fig. 1 .

The situation, however, has been changed by recent advancement of laser crystallization process. Advanced laser crystallization process (2-5) has made it possible to control location of a large Si grains two dimensionally and to position the TFT channel inside the grain, thereby realizing "single-grain Si TFTs". It should be noted that lateral grain growth process only, e.g., SLS (6), CLC (7), SELAX (8), cannot full fill the conditions. The single-grain (SG) Si TFTs obtained by the $\mu$-Czochralski process $(2,5)$ exhibits indeed a field effect mobility as high as the SOI counterpart. With a maximum process temperature of $350^{\circ} \mathrm{C}$, transistors that were fabricated inside the location-controlled grains exhibit mobility of $600 \mathrm{~cm}^{2} / \mathrm{Vs}$ (9) and $280 \mathrm{~cm}^{2} / \mathrm{Vs}$ for electrons and holes, respectively. As shown in Fig. 1, the high performance SG-TFTs are going to open new markets for the TFTs, such as RF wireless display, 3D-ICs with monolithic integration and flexible electronics. The 3D-ICs in particular will break-through problems of ULSI 
with the conventional 2D-ICs, i.e., the long transit delay in the interconnects and the limited integration of different functions. The 3D-ICs with SG-TFTs will be the ultimate cooperation between TFT and ULSI, which originated from the single invention.

In this paper we first review the $\mu$-Czochralski process, which realizes the $2 \mathrm{D}$ locationcontrol of large Si grains. We show that defects inside the location controlled Si islands are only coincident site lattice (CSL) boundaries, which are not electrically active. TFTs fabricated inside the crystalline islands of $6 \mu \mathrm{m}$ show a mobility $\left(600 \mathrm{~cm}^{2} / \mathrm{Vs}\right)$, despite of the low-temperature $\left(<350^{\circ} \mathrm{C}\right)$ process. By applying a tensile stress into the grain, the mobility surpasses even that of the SOI counterparts. We show also a way to control crystallographic orientation of the location-controlled $\mathrm{Si}$ grains and to minimize variation of the properties. We will also demonstrate RF low-noise amplifier and CMOS inverters with stacked two SG-TFT.

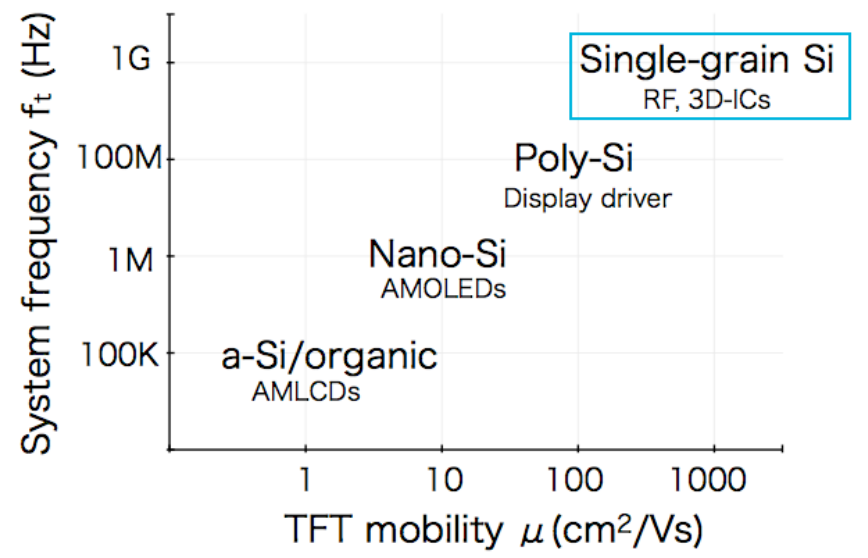

Figure 1. Various system applications as a function of TFT mobility.

\section{Single-grain Si TFTs}

The $\mu$-Czochralski (grain-filter) process

Excimer laser crystallization (ELC) is a well-established method for producing polySi films on non-heat resistant substrates (10). As shown in Fig. 1, applications of the poly-Si TFTs are limited to display driver due to the low field-effect mobility of around $100 \mathrm{~cm}^{2} / \mathrm{Vs}$. The low mobility is due to potential barriers formed at random grain boundaries (GBs) which trap carriers. Lateral grain growth (6-8) can reduce the effect of GBs, however, the mobility is still limited due to inevitable incorporation of the random GBs. If the location of the silicon islands is controlled, the position of the channel region of FETs can also be aligned inside the island. The 2D location control of Si grains can eliminate inclusion of the random GBs and enables formation of single-grain (SG) TFTs.

A few have been reported the 2D location control of Si grains and formation of TFTs inside those (2-5). Among them the $\mu$-Czochralski (grain-filter) process $(2,5)$ has advantages in terms of the wide energy density window for obtaining the $2 \mathrm{D}$ location control, and alignment accuracy over the other methods. 




(c)

(d)

Figure 2. Schematic for the $\mu$-Czochralski (grain-filter) process and single-grain Si TFTs

As depicted in Fig. 2, the $\mu$-Czochralski process has a locally increased thickness of the a-Si film in a cavity (grain-filter) in a substrate. Upon excimer-laser irradiation, the grain filter melts non-completely, whereas the surrounding melts completely. During vertical growth of the pre-existing seeds in the grain filter, occlusion of grains occurs reducing the number of growing grains. By increasing the aspect ratio, only single grain can be filtered out from many pre-existing fine grains. Experimental details for forming the grain-filter structure has been described elsewhere $(2,9)$. The hole diameter is approximately $100 \mathrm{~nm}$. A $250 \mathrm{~nm}$ thick a-Si film is then deposited by LPCVD. A single $56 \mathrm{~ns}$ long $\mathrm{XeCl}(308 \mathrm{~nm})$ excimer-laser light irradiates the Si surface.

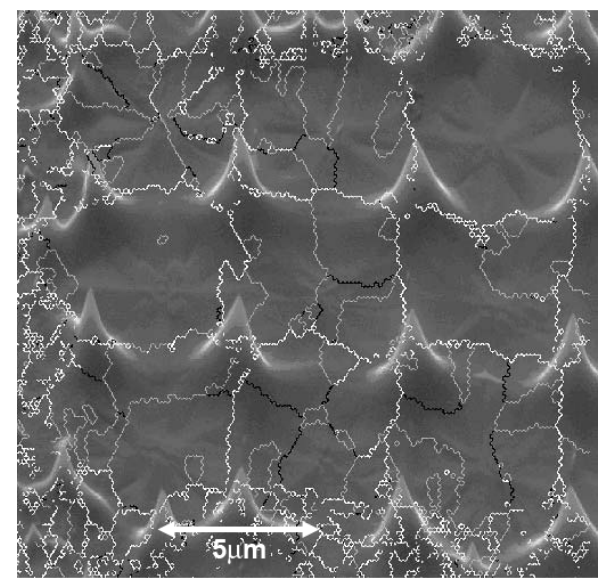

Figure 3. SEM image and EBSD mapping of a grid of location-controlled grains showing the CSL GBs $\Sigma 3$ (gray) and $\Sigma 9$ (black) and the random GBs (white).

A SEM image of location-controlled grains is shown in Fig. 3. Si grains of $6 \mu \mathrm{m}$ per side are thereby obtained in predetermined positions via the $\mu$-Czochralski process. Although random grain boundaries are absent inside the grains, some of the grains have planar defects which are generated from either the center of the film or from the rim of the grain filter. Electron backscattering diffraction (EBSD) analysis of such grains showed that the planer defects generating from the holes are mainly $\Sigma 3$ coincidence site lattice (CSL) boundaries, followed by $\Sigma 9$ and $\Sigma 27$. TEM (11) revealed that the boundary plane for the $\Sigma 3$ CSL boundary is predominantly $\{111\}$. 
Local electrical characterization of the grain boundaries

We have directly measured local electrical properties of the CSL boundaries in the location-controlled Si islands (12). Figure 4 depicts a scanning capacitance microscopy (SCM) image and $\mathrm{C}-\mathrm{V}$ measurement at a random GB, $\Sigma 9$ and $\Sigma 3$ CSL boundaries. It should be noted that the grain filter diameter is widened to $500 \mathrm{~nm}$ to intentionally incorporate the random GBs. Three crosses represented in the SCM image indicate points used for the $\mathrm{C}-\mathrm{V}$ measurements. One can find the clear difference on $\mathrm{C}-\mathrm{V}$ characteristics between the curves for the three boundaries. Capacitance drop as well as slope is largest for the curve of $\Sigma 3$, and smaller for $\Sigma 9$, followed by one for random GBs. The smaller drop and slope of the $\mathrm{C}-\mathrm{V}$ curve indicate higher density of state within forbidden gap and/or tails of conduction band. This result suggests that the $\Sigma 9$ boundary has trap states and electrical activity; however, it is much less than that of random boundary. Similar results have been obtained with SSRM (13). Those are consistent with our ab-initio atomic modeling result; $\{111\} \Sigma 3$ CSL boundary has no states in the forbidden gap and at band tails due to absence of irregular coordination at the boundary.
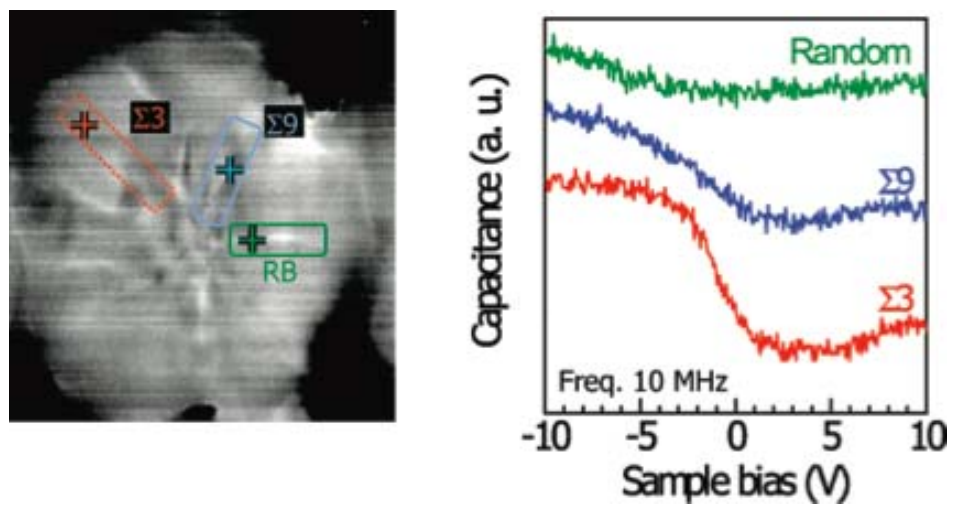

Figure 4. SCM mapping image of the location control of grains (left) and C-V curves (right) at various CSL boundaries indicated in the image.

\section{$\underline{\text { TFT fabrication and characterization }}$}

TFTs are fabricated inside the location-controlled grains obtained by the $\mu$ Czochralski process. For investigation of the CSL boundary effect, we have varied position of channel inside the grain, as depicted in the inset of Fig 5 (b). We have shifted the TFT channel position in the island with respect to the grain filter. In X position, the radially grown CSL boundary is parallel to the carrier flow direction. Possible CSL boundary of $\mathrm{Y}$ is perpendicular to the carrier flow direction.

Detailed TFT process was explained elsewhere $(2,9)$. Here we describe it shortly. After the location-control of the grain, the Si film is patterned into islands. The transistors are designed so that a single grain covers the entire channel area of a TFT. A $120 \mathrm{~nm}$ thick ECR-PECVD $\mathrm{SiO}_{2}$ layer was deposited as a gate insulator at room temperature and annealed in water vapor at $333^{\circ} \mathrm{C}$. The source and drain are implanted with $\mathrm{P}$ ion $\left(1 \times 10^{16} \mathrm{~cm}^{-2}\right)$, which is then activated by the excimer-laser annealing. The maximum process temperature is $350^{\circ} \mathrm{C}$. As a reference, TFTs on silicon on insulator (SOI) with $\{100\}$ orientation were fabricated with the same process conditions.

The SG TFTs at the X position give an average field-effect mobility $\mu_{\mathrm{FEe}}$ of $597 \pm 101$ $\mathrm{cm}^{2} / \mathrm{Vs}$, which is well comparable with that of the SOI $\left(727 \pm 18 \mathrm{~cm}^{2} / \mathrm{Vs}\right)$. The high 
mobility of the SG-TFTs is attributed to the fact that the carriers do not experience the CSL boundaries because it is parallel to the direction of current flow. The mobility is slightly lower and the standard deviation is higher than those of the SOI-TFTs. Those are because surface orientation of the location-controlled grains is random from which some orientations reduce the mobility due to higher effective mass. When the channel position is at $\mathrm{Y}$, the average $\mu_{\mathrm{FEe}}$ decreases to $528 \mathrm{~cm}^{2} / \mathrm{Vs}$, which is caused by the CSL boundaries perpendicular to the carrier flow. This leads to the conclusion that reduction of the mobility by the presence of the CSL boundaries is only $10 \%$ in average.

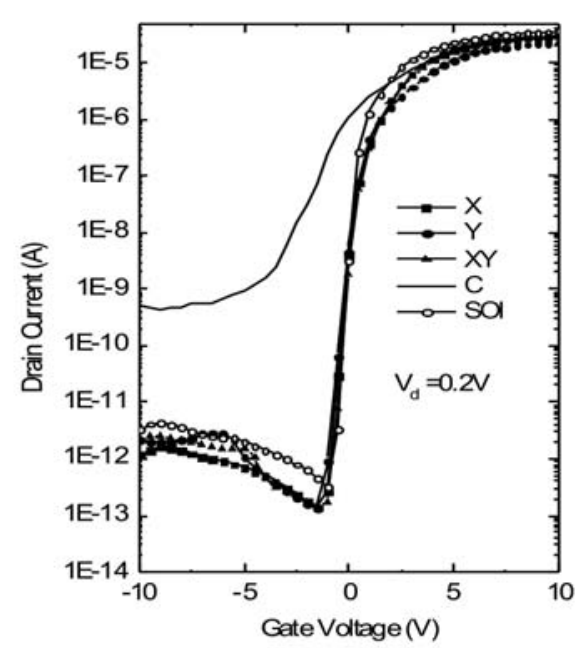

(a)



(b)

Figure 5. Transfer characteristics (a) and field-effect mobility of n-channel single-grain $\mathrm{Si}$ TFTs fabricated at various positions in the location controlled grain.

\section{$\underline{\text { High mobility by tensile strain }}$}

Figure 6 shows the electron field-effect mobility as a function of energy density of excimer-laser. It can be seen that the mean mobility about $600 \mathrm{~cm}^{2} / \mathrm{Vs}$ is obtained for a wide range of energy densities. The single-grain is obtained in the wide energy density range where only melt depth changes in the depth of the grain filter. The wide energy density window is a very important advantage of the $\mu$-Czochralski process.

At the highest energy density, we obtained a mean field-effect mobility of as high as $883 \mathrm{~cm}^{2} / \mathrm{Vs}$ for the $\mathrm{X}$ position. The peak value at the $\mathrm{X}$ position even reaches to 1200 $\mathrm{cm}^{2} / \mathrm{Vs}$. A mean field-effect mobility value of $814 \mathrm{~cm}^{2} / \mathrm{Vs}$ and $773 \mathrm{~cm}^{2} / \mathrm{Vs}$ is obtained for $\mathrm{C}$ and $\mathrm{Y}$ position, respectively. For p-channel SG-TFTs, we achieved a mean fieldeffect mobility value of $320 \mathrm{~cm}^{2} / \mathrm{Vs}$, with a peak value of $500 \mathrm{~cm}^{2} / \mathrm{Vs}$. Those extremely high nobilities can be explained by the tensile stress in the location-controlled grains (14) with a combination of high quality $\mathrm{Si} / \mathrm{SiO}_{2}$ interface. At the highest energy, the grain filter finally completely melts (11) during the excimer-laser irradiation. Since there is no seed left in the grain filter, the molten-Si should wait for the spontaneous nucleation to solidify. The molten-Si solidifies with much higher solidification velocity due to the severe undercooling, compared to the non-complete melt condition, building up the 
tensile stress in the grain. With micro-Raman technique, we have measured a tensile stress of $1.2 \mathrm{GPa}$ in the grain.



Figure 6. Mobility of the SG-TFT as a function of laser energy density for various positions in the grain

\section{Location and Orientation Control of Si Grains}

Both location- and orientation-control of Si grains has been achieved by combining metal induced lateral crystallization (MILC) and the $\mu$-Czochralski process (15). The former controls crystallographic orientation of grains to (110) which is used as a seed crystal whereas the latter controls the 2D location of the grains. After the grain-filter formation, $\mathrm{Ni}$ was deposited by sputtering and patterned into an island which has a distance of $20 \mu \mathrm{m}$ away from the grain filter. After pre-annealing and removing the $\mathrm{Ni}$, the sample was further annealed at $600^{\circ} \mathrm{C}$ for $4 \mathrm{~h}$ in $\mathrm{N}_{2}$ ambient for the MILC. Figure 7(a) shows the SEM image after the MILC. The MILC poly-Si, which has needle-like grains, covered the whole matrix of grain-filter. The total length of lateral crystallization was 67 $\mu \mathrm{m}$. From EBSD, it was found that the MILC has surface crystallographic orientation of (110). Then the thin layer of the MILC poly-Si, which is contaminated by the $\mathrm{Ni}$, was etched away. In the grain filter the MILC poly-Si was still left. After that, a new $250 \mathrm{~nm}$ thick a-Si layer was deposited by sputtering and the sample was crystallized with one shot of excimer-laser at a substrate temperature of $450^{\circ} \mathrm{C}$.



(a)



(b)

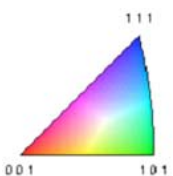

Figure 7. (a) SEM image of Si right after the MILC process and (b) EBSD mapping of the location-controlled grains after laser crystallization of the sample (a). 
After the laser crystallization, we found that the location-controlled grains with $6 \mu \mathrm{m}$ was obtained and the needle shape defects disappeared. Fig.7 (b) shows EBSD mapping of eight location-controlled grains after the laser crystallization. We see that all the eight grains have (110) orientation with a few CSL boundaries at the edge which indicate the (110) MILC poly-Si has grown into the grain-filter and has seeded the laser crystallization inheriting the orientation. It was found that $\mathrm{Ni}$ concentration $10^{17} \mathrm{~cm}^{-3}$ was decreased below the SIMS detection limit $\left(5 \times 10^{15} \mathrm{~cm}^{-3}\right)$ owing to the removing process of the MILC poly-Si layer.

Using the orientation controlled grains, the SG TFTs were fabricated with the similar process described above, except for the change of gate $\mathrm{SiO}_{2}$ into $100 \mathrm{~nm}$ ICP-PECVD $\mathrm{SiO}_{2}$. The channel width and length was both $2 \mu \mathrm{m}$. Table I shows statistical variation of the TFT characteristics values. With the grain orientation control, we have obtained an average mobility of $507 \mathrm{~cm}^{2} / \mathrm{Vs}$ with a standard deviation of $32 \mathrm{~cm}^{2} / \mathrm{Vs}(6 \%)$, which is an great improvement compared to without the orientation control (25\%) (9) and approaches to that of the SOI counterpart (2\%). The average mobility is decreased due to the (110) orientation, whereas the uniformity is improved owing to orientation control. It should be noted that we have recently succeeded to control the orientation into (100) as well (16).

Table I. SG-TFTs by $\mu$-Czochralski with/w.o the MILC process

\begin{tabular}{cccc}
\hline & $\begin{array}{c}\boldsymbol{\mu} \text {-Czochralski } \\
\text { only }\end{array}$ & $\begin{array}{c}\text { MILC }+\boldsymbol{\mu}- \\
\text { Czochralski }\end{array}$ & SOI \\
\hline $\begin{array}{c}\text { Average mobility } \\
\left(\mathrm{cm}^{2} / \mathrm{Vs}\right)\end{array}$ & 579 & 507 & 727 \\
Deviation (cm2/Vs) & $139(25 \%)$ & $32(6 \%)$ & $18(2 \%)$ \\
$\mathrm{S}(\mathrm{V} / \mathrm{dec})$ & 0.45 & 0.24 & 0.18 \\
$\mathrm{~V}_{\text {th }}(\mathrm{V})$ & 1.55 & 0.4 & 1.1 \\
Leakage current $(\mathrm{A})$ & $5.70 \mathrm{E}-12$ & $2.45 \mathrm{E}-12$ & $1.7 \mathrm{E}-12$ \\
\hline
\end{tabular}

\section{RF and 3D integrated circuits}

\section{$\underline{\text { RF Circuits }}$}

Using the high performance SG-TFTs we have designed and fabricated RF low-noise amplifier with on-chip spiral inductors to demonstrate its potential for realizing high performance analog/RF applications on large-area substrates (17). Here a modified BSIM-SOI transistor model (18) is used for the simulation of the SG-TFTs. The BSIMSOI with a proper modification of the mobility is carried out. The model has been verified for $\mathrm{n}$ - and $\mathrm{p}$-channel $\mathrm{DC}$ and low frequency $\mathrm{AC}$ conditions as well by comparison with measurement results. 
Firstly $\mathrm{n}$ - and p-channel SG-TFTs and passive devices have been integrated and measured over the frequency range of $50 \mathrm{MHz}$ to $20 \mathrm{GHz}$. Multiple finger devices achieve a sufficient transconductance $\mathrm{g}_{\mathrm{m}}$ and gain at $\mathrm{RF}$ with a low extrinsic gate resistance of Al. Fig. 8(a) shows the chip photograph of a SG-TFT with 20 fingers and 5 rows used for RF characterization and, Fig. 8(b), a cascode dual-gate SG-TFT amplifier. Fig. 9(a) reveals that the measured current gain-bandwidth $f_{\mathrm{T}}$ is $5.45 \mathrm{GHz}$ at a drainsource $V_{D S}$ and gate-source $V_{G S}$ bias of $3 \mathrm{~V}\left(I_{D}=25 \mathrm{~mA}\right.$ and $\left.g_{m}=16 \mathrm{mS}\right)$. The corresponding unity-power-gain frequency $f_{\max }$ is $11.45 \mathrm{GHz}$. With the unity gain bandwidths in the 5 to $6 \mathrm{GHz}$ range, amplifiers can be designed in the sub- $1 \mathrm{GHz}$ frequency range with expected gains in the $10 \mathrm{~s}$ of $\mathrm{dBs}$.

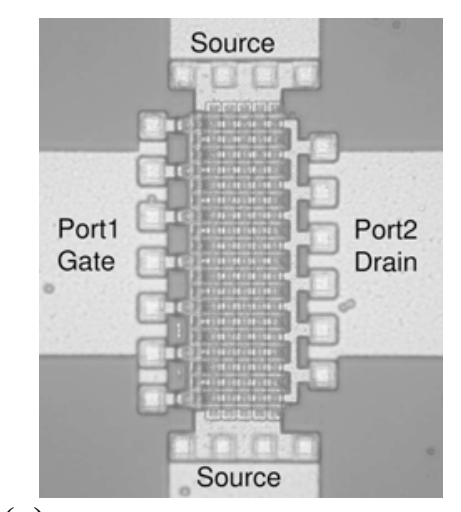

(a)

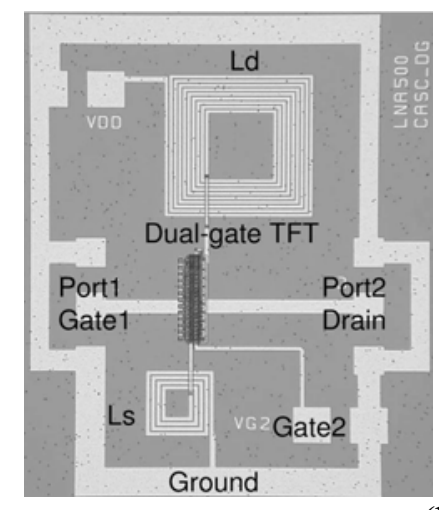

(b)

Figure 8. Chip photographs of SG-TFT with total width of $500 \mu \mathrm{m}$ and $\mathrm{L}=1.5 \mu \mathrm{m}$ used for RF characterization (a) and cascode amplifier with dual-gate $\operatorname{SGTFTs(b).~}$
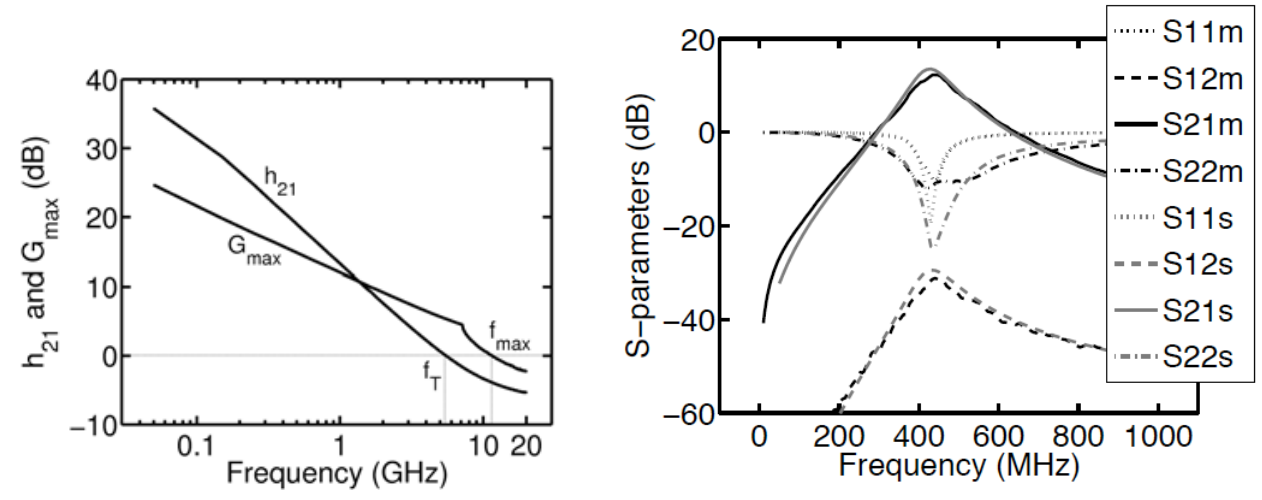

Figure 9. Measured RF performance of the SG-TFT: $h_{21}$ and $\mathrm{G}_{\mathrm{MAX}}$ as function of frequency (a) and measured and simulated S-parameters (b) of the cascode RF amplifier.

A cascode dual-gate SG-TFT amplifier has been designed with $433 \mathrm{MHz}$ ISM band. The cascode amplifier circuit uses as load a $35 \mathrm{nH}$ on-chip inductor designed for a resonance of $430 \mathrm{MHz}$. As shown in Fig. 9(b), the $433 \mathrm{MHz}$ ISM amplifier achieves useful RF gain of more than $10 \mathrm{~dB}$, good isolation (better than $25 \mathrm{~dB}$ ), and IIP3 of 10 $\mathrm{dBm}$. Such an amplifier could also be used in the IF stage of a transmitter or receiver operating at a higher RF front-end frequency. 


\section{$\underline{3 \mathrm{D}-\mathrm{ICs}}$}

We have fabricated CMOS inverters with two layer SG-TFTs (19). The process flow starts with formation of bottom SG-TFT layer using the $\mu$-Czochralski process. For the gate oxide, we deposited a $30 \mathrm{~nm}$-thick ICP enhanced CVD oxide at $250^{\circ} \mathrm{C}$. The bottom layer is then passivated by ILD of $2 \mu \mathrm{m}$ thick PECVD-TEOS oxide grown at $350^{\circ} \mathrm{C}$. The ILD was planarized using the CMP with the final roughness of $5 \mathrm{~nm}$ (20). Processing the second layer starts also with the $\mu$-Czochralski process and follows the same process flow as the bottom layer. After planarization of a passivation $\mathrm{SiO}_{2}$ by etch-back process, vias were opened to connect the bottom layer to pads and also to top layer contacts. Finally interconnects are formed by a $675 \mathrm{~nm}$-thick $\mathrm{Al}$ sputtered at $350^{\circ} \mathrm{C}$. The maximum process temperature is $350^{\circ} \mathrm{C}$ after the a-Si LPCVD step.

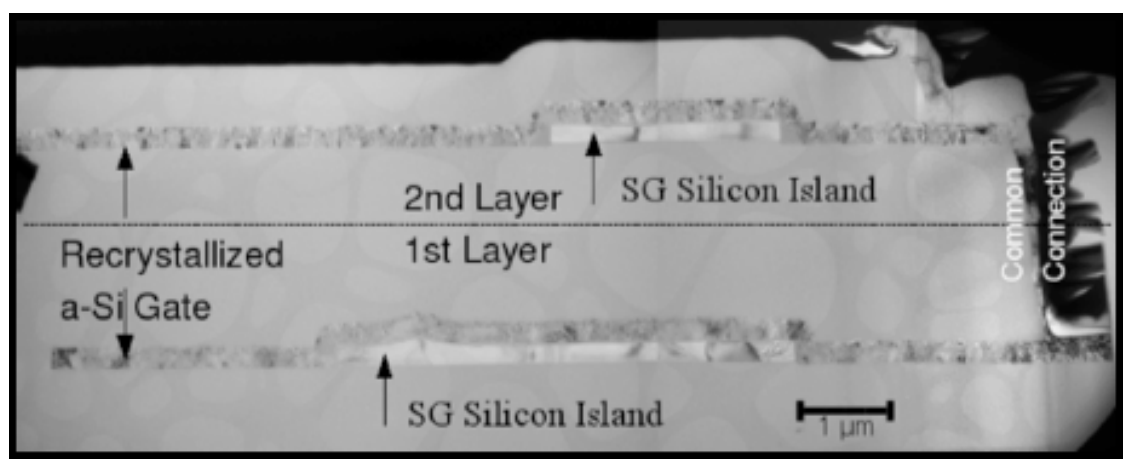

Figure 10. TEM image of inverter with two-layer SG-TFTs.

Figure 10 shows a cross-sectional TEM image of the fabricated CMOS inverters with two SG-TFT layers having the nMOS on top of the pMOS. The cross section is made along the gate width direction. The width of the pMOS is $4.2 \mu \mathrm{m}$, twice of the nMOS. The gate length of both transistors is $1.5 \mu \mathrm{m}$. The single-grain channels, the poly-Si gates at the both bottom and top layers, and the common connection can clearly be seen.

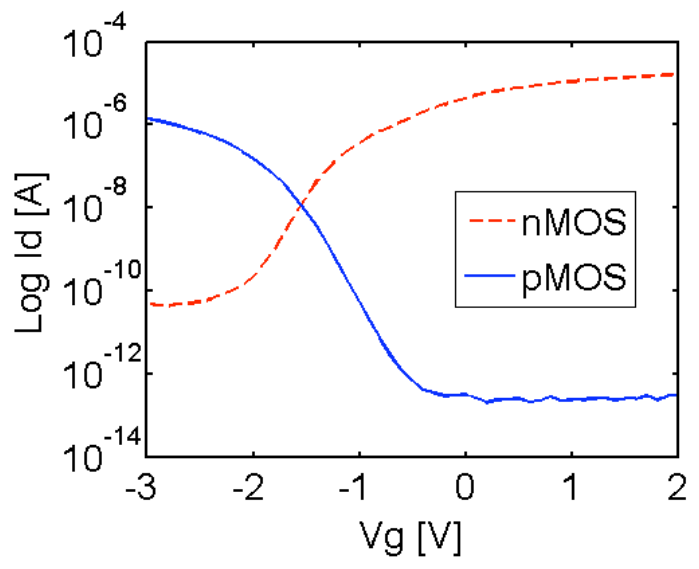

(a)

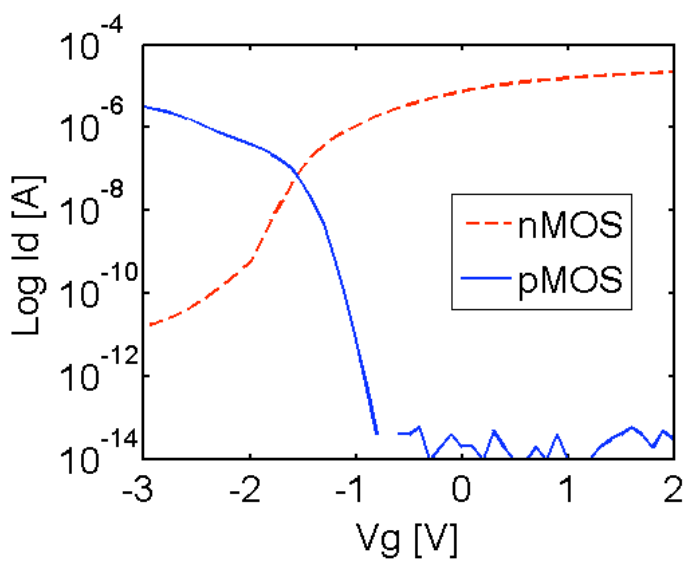

(b)

Figure 11. Transfer characteristics of the bottom (a) and top (b) SG TFTs 
Figure 11 shows transfer characteristics of the bottom (a) and top (b) SG TFTs for the both n- and p-channels. A good matching of the transfer characteristics between the top and bottom transistors is observed. The top layer field-effect mobilities are 565 and 159 $\mathrm{cm}^{2} / \mathrm{Vs}$ and bottom layer mobilities are 393 and $141 \mathrm{~cm}^{2} / \mathrm{Vs}$, for the nMOS and pMOS devices, respectively. Table II summarizes the average characteristic values for different devices on each layer. The devices on the top layer have slightly better performance than those on the bottom layer. This is due to process variations such as better gate patterning



(a)

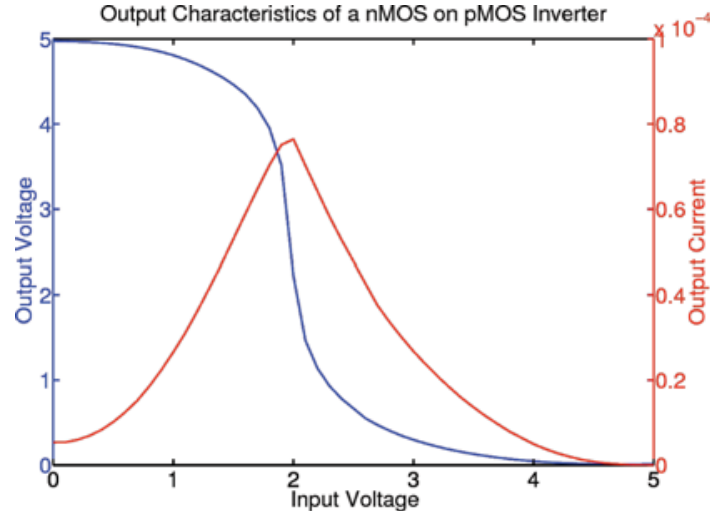

(b)

Figure 12. Output characteristics of CMOS inverters with pMOS at the (c) top and (d)

by dry etching for the top. Main reason for the higher leakage of the bottom layer TFTs, is accidental over-etching of Si island during gate patterning process.

The output characteristics of the CMOS inverters are also shown in Figure 12. Two different CMOS configurations have been made: nMOS on pMOS (a) and pMOS on nMOS (b). For both types, switching voltage of the inverters lies around $2 \mathrm{~V}$. The input signal swings from 0 to $5 \mathrm{~V}$, and so does the output. The first type shows slightly better inverter characteristics, which may be due to the process variation.

Table II. TFT properties of the two layer SG-TFTs.

\begin{tabular}{cccccc}
\hline Type of device & $\begin{array}{c}\text { Mobility } \\
{\left[\mathbf{c m}^{2} / \mathbf{V s}\right]}\end{array}$ & $\mathbf{S}[\mathbf{m V} / \mathbf{d e c}]$ & Vth $[\mathbf{V}]$ & $\mathbf{I d}(\mathbf{m a x})[\mathrm{A}]$ & $\mathbf{I}_{\text {leak }}[\mathrm{A}]$ \\
\hline nMOS Top & 565 & 245 & -0.8 & $2.19 \mathrm{E}-05$ & $5.39 \mathrm{E}-12$ \\
pMOS Top & 159 & 95 & -2.4 & $1.61 \mathrm{E}-05$ & $2.80 \mathrm{E}-13$ \\
nMOS Bottom & 393 & 280 & -0.6 & $1.81 \mathrm{E}-05$ & $1.49 \mathrm{E}-10$ \\
pMOS Bottom & 141 & 151 & -2 & $1.43 \mathrm{E}-05$ & $9.2 \mathrm{E}-13$ \\
\hline
\end{tabular}

\section{Conclusions}

We demonstrated that the single-grain Si TFT through the $\mu$-Czochralski process can be used for wireless RF and also 3D ICs. Large Si grains of $6 \mu \mathrm{m}$ per side are thereby obtained in predetermined positions via the $\mu$-Czochralski process. We show that defects inside the location controlled Si islands are only CSL boundaries of which the most is electrically inactive. The SG Si TFTs fabricated inside the crystalline islands of $6 \mu \mathrm{m}$ show a high mobility $\left(600 \mathrm{~cm}^{2} / \mathrm{Vs}\right)$ in a wide energy density window, despite of the lowtemperature $\left(<350^{\circ} \mathrm{C}\right)$ process. By applying a tensile strain into the grain, the mobility surpasses even that of the SOI counterparts. We have succeeded in controlling 
crystallographic orientation of the location-controlled Si grains, by combination of metal induced lateral crystallization and the $\mu$-Czochralski process. Owing to the (110) surface orientation control, uniformity of device properties approaches to the level of the SOI counterpart. We also demonstrated the RF low-noise amplifier and the 3D-ICs by CMOS inverters with stacked two SG-TFT. The cut-off frequency of the RF device is $5.5 \mathrm{GHz}$ with a channel length of $1.5 \mu \mathrm{m}$. This will open several new applications in TFTs of RF wireless communication, 3D-ICs with device level integration.

\section{Acknowledgments}

The authors would like to thank the Dutch Technology Foundation STW for their financial support and the cleanroom staff of DIMES technology center for their support during the fabrication of these devices.

\section{References}

1. O. Heil, UK Patent No. 439457 (1935)

2. R. Ishihara, P. C. van der Wilt, B. D. van Dijk, A. Burtsev, F. C. Voogt, G. J. Bertens, J. W. Metselaar, and C. I. M. Beenakker, Proc. SPIE, 4295, 14 (2001)

3. M.A. Crowder, P.G. Carey, P.M. Smith, R.S. Sposili, H.S. Cho, J.S. Im, J.S., IEEE Electron Device Lett., 19, 8, 306 (1998)

4. T. Endoh, 214th ECS Meeting, Thin Film Transistors 9 (TFT 9), \#2275 (2008)

5. R. Ishihara, Vikas Rana, M. He, Y. Hiroshima, S. Inoue, W. Metselaar and K. Beenakker, Solid State Electronics, 52, 353-358 (2008)

6. Y. H. Jung, J. M. Yoon, M. S. Yang, W. K. Park, and H. S. Soh, Mater. Res. Soc. Symp. Proc. 621, Q9.14.1 (2000)

7. A. Hara, F. Takeuchi, M. Takei, K. Suga, K. Yoshino, M. Chida, Y. Sano, and N. Sasaki, Jpn. J. Appl. Phys.. vol. 41, pp. L311-3

8. M. Tai, M. Hatano, S. Yamaguchi, T. Noda, S.K. Park, T. Shiba, and M. Ohkura, IEEE Trans. Electr. Devices, vol. 51, pp. 934-939, 2004.

9. V. Rana, R. Ishihara, Y. Hiroshima, D. Abe, S. Inoue, T. Shimoda, J.W. Metselaar and C.I.M. Beenakker, IEEE Trans. Electron Devices, 52, 12, 2622 (2005)

10. T. Sameshima, S. Usui and M. Sekiya: IEEE Electron Device Lett. 7 (1986) 276.

11. R. Ishihara, D. Danciu, F. Tichelaar, M. He, Y. Hiroshima, S. Inoue, T. Shimoda, J.W. Metselaar and C.I.M. Beenakker, J. Crystal Growth, 299, 2, 316 (2007)

12. N. Matsuki, R. Ishihara, A. Baiano and C.I.M. Beenakker, Appl. Phys. Lett., 93 062102 (2008)

13. N. Matsuki, R. Ishihara, A. Baiano and C.I.M. Beenakker, 14th Int. Display Workshops (IDW'07), 2, p. 489-492 (2007)

14. A. Baiano, R. Ishihara and K. Beenakker, 2009 MRS Spring meeting (2009) A12.1.

15. T. Chen, R. Ishihara and C.I.M. Beenakker, 15th Int. Display Workshops (IDW '08)

16. Tao Chen, R. Ishihara and C.I.M. Beenakker, 214th ECS Meeting, Thin Film Transistors 9 (TFT 9), \#2285 (2008)

17. N. Saputra, M. Danesh, A. Baiano, R. Ishihara, J. R. Long, N. Karaki and S. Inoue, J. Solid State Circuits, 43, 7, 1563-1576 (2008) 
18. A. Baiano, M. Danesh, N. Saputra, R. Ishihara, J. Long, W. Metselaar, C.I.M. Beenakker, N. Karaki, Y. Hiroshima and S. Inoue, J. Solid State Electronics, 52, 9, Year (2008) 1345-1352

19. M.R.T. Mofrad, J. Derakhshandeh, R. Ishihara and K. Beenakker, ESSDERC2008 Fringe (2008)

20. J. Derakhshandeh and M.R. Tajari Mofrad and R. Ishihara and J. van der Cingel and C.I.M. Beenakker, J. Korean Phys. Soc., 54-1, (2009) 432 